\title{
Shift work is associated with metabolic syndrome in male steel workers-the role of resistin and WBC count-related metabolic derangements
}

\author{
Yung-Chuan Lu, ${ }^{1,7 \dagger}$, Chao-Ping Wang ${ }^{2,7 \dagger}$, Teng-Hung Yu², I-Ting Tsai ${ }^{4,6}$, Wei-Chin Hung ${ }^{2}$, I-Cheng Lu ${ }^{5}$, \\ Chia-Chang Hsu ${ }^{3}$, Wei-Hua Tang ${ }^{9}$, Jer-Yiing Houng ${ }^{8}$, Fu-Mei Chung ${ }^{2}$ and Mei-Chu Yen Jean ${ }^{5,6,7^{*}}$
}

\begin{abstract}
Aims: There is increasing evidence linking a shift work schedule with various adverse health effects. The present study aimed to examine the relationship between shift work and the metabolic syndrome (MetS) in male steel workers, and also the possible mechanism of shift work-related metabolic derangements.

Methods: A total of 1732 men aged $42 \pm 8$ years were enrolled in this cross-sectional study, including 862 day workers and 870 shift workers. Circulating levels of resistin were measured by ELISA using monoclonal specific antibodies.

Results: The shift workers had higher rates of MetS and its components (central obesity, hypertension, and hypertriglyceridemia) than the day workers. In multiple logistic regression analysis, shift work was independently associated with MetS. In further analysis, the shift workers had elevated circulating levels of resistin ( $13 \pm 10 \mathrm{vs} .10 \pm 7 \mathrm{ng} / \mathrm{mL}$ ) and total white blood cell (WBC) count (6.865 \pm 1.819 vs. $\left.6.304 \pm 1.54710^{9} / L\right)$ than the day workers. In addition, both resistin level and total WBC count were significantly associated with shift work, MetS, and its components (body mass index, fasting glucose, triglyceride, and high-density lipoprotein-cholesterol levels), and plasma resistin levels were significantly associated with total WBC count $(\beta=0.34, p<0.0001)$.
\end{abstract}

Conclusion: Shift work was independently associated with MetS in male steel workers. Resistin and WBC count were associated with shift work-related metabolic derangements.

Keywords: Steel workers, Shift work, Metabolic syndrome, Body mass index, Fasting glucose, Triglyceride, Highdensity lipoprotein-cholesterol, Resistin, White blood cell count

\section{Background}

Shift work is defined that takes place on a schedule outside the traditional 9 a.m. -5 p.m. day. It can involve evening or night shifts, early morning shifts, and rotating shifts [1]. Shift work is increasing worldwide, and as many as $20 \%$ of workers in industrialized nations are shift workers [2]. Shift work has been reported to disrupt

*Correspondence: gene6623@yahoo.com.tw; ed100977@edah.org.tw †Yung-Chuan Lu and Chao-Ping Wang contributed equally to this work ${ }^{5}$ Department of Occupational Medicine, E-Da Hospital, I-Shou University, No. 1, Yi-Da Rd, Jiau-Shu Village, Yan-Chao Township, Kaohsiung 82445, Taiwan

Full list of author information is available at the end of the article the circadian rhythm, sleep and work-life balance, and to increase the risk of metabolic syndrome (MetS) [3], coronary heart disease [4], mental and behavioral disorders [5], and sleep disturbances [6]. The major function of the circadian system is internal cycling of physiological and metabolic events [7]. Many physiological processes display a day-night rhythms, and feeding behaviour, lipid and carbohydrate metabolism and blood pressure are subject to daily variations.

The prevalence of MetS is increasing globally, including Taiwan. The components of MetS including dyslipidemia, dysglycemia, high blood pressure, and being overweight/obese tend to cluster together, and they are 
thought to be related to lifestyle habits including physical activity, nutrient intake, alcohol consumption, and smoking [8-11]. Few studies have examined the relationships between shift work and MetS taking into consideration the various factors associated with shift work that might lead to MetS. In addition, shift work may be responsible for increased body fatness and inflammatory markers, higher blood pressure levels, and chronic low-grade inflammation to play an important role in the development of MetS [3, 12-16].

The detrimental effects of shift work on MetS and the induction of inflammatory cytokines and associated factors raise the possibility that shift work may increase the risk of MetS. To clarify this hypothesis, we investigated the association between shift work and features of National Cholesterol Education Program Adult Treatment Panel III (NCEP-ATP III)-defined MetS [17]. The possible mechanisms by which shift work affects MetS were also investigated by measuring inflammatory markers including resistin and peripheral white blood cell (WBC) count in a large population-based sample of male Chinese steel workers.

\section{Subjects and methods \\ Study design and participants}

This study was conducted at a hospital from January 1 to December 31, 2016. Workers at two steel plants in southern Taiwan who underwent annual health examinations were included in this cross-sectional survey study. In total, 1732 men (862 day workers, 870 backward rotating shift workers) of self-reported Chinese ancestry aged $42 \pm 8$ years were selected as the study cohort, after 69 had been excluded due to a history of acute or chronic inflammatory disease, allergic disease, autoimmune disease, or cancer. The work schedule was classified as daytime work (8:00-17:00) and shift work, which included rotating shifts of night (23:00-7:00), afternoon (15:0023:00), and morning (7:00-15:00) shifts. None of the subjects changed schedule during the study period, and they were all engaged in this schedule at baseline. This study was approved by the Human Research Ethics Committee of Kaohsiung E-Da Hospital, I-Shou University. Written informed consent was obtained from all participants.

\section{Data collection and measures}

Self-administered questionnaires were distributed and collected on the day of the health examination. Information on basic demographic characteristics and lifestyle, such as age, sex, job type, sleep quality, health condition, physical exercise, smoking habit, and alcohol consumption were ascertained using the questionnaire. Physical exercise was assessed by the question "How often did you exercise during the past month?" The response options were: hardly ever, once, and twice or more. For working schedule, the participants were asked whether they were daytime workers $(8: 00-17: 00)$ or shift workers working rotating shifts of morning (7:00-15:00), afternoon (15:00-23:00), and night (23:00-7:00) shifts. Sleep quality was assessed by the question "How often did you have poor sleep during the past month?" The response options were: almost never, sometimes, and often or almost always.

The smoking status of the subjects was classified as never having smoked, former smoker (quit smoking for at least 1 year), or current smoker. Alcohol drinking and betel quid chewing status were classified as never drink or chew betel quid, former drinker or betel quid chewer (quit drinking or betel quid chewing for at least 1 year), or current drinker or betel quid chewer. In this study, former and current drinkers and betel quid chewers were analyzed as a single group [18]. In addition, body mass index (BMI) was calculated as weight (in kilograms) divided by height (in meters) squared. MetS was defined according to the NCEP-ATP III with a modified definition of central obesity [17]. MetS was diagnosed when a subject met three or more of the following criteria: (1) arterial blood pressure $\geq 130 / 85 \mathrm{mmHg}$, (2) central obesity (waist circumference, males $\geq 90 \mathrm{~cm}$; females $\geq 80 \mathrm{~cm}$ ), (3) serum triglyceride level $\geq 150 \mathrm{mg} / \mathrm{dL}$, (4) serum high-density lipoprotein cholesterol (HDL-C) $<40 \mathrm{mg} / \mathrm{dL}$ in males or < $50 \mathrm{mg} / \mathrm{dL}$ in females; and (5) fasting plasma glucose concentration $\geq 100 \mathrm{mg} / \mathrm{dL}$ or a previous diagnosis of type 2 diabetes.

\section{Laboratory measurements}

Peripheral blood samples were taken from the antecubital vein of the workers after fasting for at least $8 \mathrm{~h}$. Complete blood cell count and levels of serum glucose, HbA1c, uric acid, and lipid profiles [including plasma triglycerides, total cholesterol, low-density lipoprotein cholesterol (LDL-C), and HDL-C] were also measured during the health checkups and were determined in all workers using standard commercial methods with a parallel, multichannel analyzer (Hitachi 7170A, Tokyo, Japan) as described in our previous report $[19,20]$. Peripheral leukocyte analysis was performed using an automated cell counter (XE-2100 Hematology Alpha Transportation System, Sysmex Corporation, Kobe, Japan). The concentrations of plasma resistin were determined using commercial enzyme immunoassay kits (Phoenix Pharmaceuticals, Belmont, CA). The intraassay coefficient of variation was $2.1-5.2 \%$ for resistin. Samples were measured in duplicate in a single experiment. 


\section{Statistical analysis}

The data are presented as the mean \pm SD. All statistical analyses were performed using SAS software (version 8.0; SAS Institute, Cary, NC). Statistical differences between variables were compared using unpaired Student's $t$-tests for normally distributed variables. Categorical variables were recorded as frequencies and/or percentages, and intergroup comparisons were analyzed using the Chi square test. Multiple logistic regression analysis was used to assess independent associations between the variables of interest and the presence of MetS. In addition, simple and multiple linear regression analyses were used to examine associations between peripheral total WBC count and resistin and the values of other parameters. All statistical analyses were two-sided, and a p value $<0.05$ was considered to be statistically significant.

\section{Results}

The clinical characteristics of the participants are presented in Table 1. Of the 1732 participants, 870 (50.2\%) had been engaged in shift work for at least 1 year. Compared to the daytime workers, significantly more shift workers were current smokers, former and current betel quid users, hardly ever engaged in physical exercise, and sometimes and often or almost always had poor sleep (all $\mathrm{p}<0.05)$. They also had higher rates of central obesity $(\mathrm{p}=0.03)$, hypertension $(\mathrm{p}=0.0002)$, hyper-triglyceridemia $(\mathrm{p}=0.04)$, and MetS $(\mathrm{p}=0.03)$ than the daytime workers. In addition, the shift workers had higher systolic blood pressure (SBP), diastolic blood pressure (DBP), BMI, waist circumference, total WBC count, and higher levels of fasting glucose, triglycerides, uric acid, and resistin than the daytime workers. Moreover, the shift workers had a lower level of HDL-C than the daytime workers (Table 2). There were no significant differences in age, HbA1C, total cholesterol, LDL-C level, percentage of participants aged 25-40 and 50-60 years, alcohol consumption, former smoking, engaging in physical exercise once per month, low HDL-C, and dysglycemia between the two groups.

Multivariate logistic regression analysis showed that shift work had an odds ratio of 2.26 for the risk of MetS $(\mathrm{p}=0.02$, Table 3$)$. In age-adjusted association analysis including inflammatory markers and risk factors for MetS, resistin was significantly positively associated with BMI $(\beta=0.14, p=0.048)$, fasting glucose $(\beta=0.24$, $\mathrm{p}=0.001)$, HbA1C $(\beta=0.15, \mathrm{p}=0.04)$, triglycerides $(\beta=0.21, p=0.01)$, shift work $(\beta=0.17, p=0.02)$, and MetS $(\beta=0.17, p=0.02)$, while total WBC count was significantly positively associated with BMI $(\beta=0.25$, $\mathrm{p}<0.0001)$, waist circumference $(\beta=0.26, \mathrm{p}<0.0001)$, SBP $(\beta=0.16, \mathrm{p}<0.0001)$, DBP $(\beta=0.15, \mathrm{p}<0.0001)$, fasting glucose $(\beta=0.09, \mathrm{p}<0.0001), \operatorname{HbA1C}(\beta=0.17$,
Table 1 Clinical characteristics of the study subjects

\begin{tabular}{|c|c|c|c|}
\hline Parameter & Shift work & Day work & $p$ value \\
\hline No & 870 & 862 & \\
\hline \multicolumn{4}{|l|}{ Age (years) (n, \%) } \\
\hline $25-40$ & $338(38.9)$ & $354(41.1)$ & 0.35 \\
\hline $40-50$ & $411(47.2)$ & $365(42.3)$ & 0.04 \\
\hline $50-60$ & $113(13.0)$ & $122(14.2)$ & 0.48 \\
\hline$>60$ & $8(0.9)$ & $21(2.4)$ & 0.02 \\
\hline \multicolumn{4}{|l|}{ Alcohol use (n, \%) } \\
\hline Never & $470(54.0)$ & $501(58.1)$ & 0.09 \\
\hline Former & $25(2.9)$ & $20(2.3)$ & 0.47 \\
\hline Current & $375(43.1)$ & $341(39.6)$ & 0.13 \\
\hline \multicolumn{4}{|l|}{ Smoking (n, \%) } \\
\hline Never & $404(46.4)$ & $506(58.7)$ & $<0.0001$ \\
\hline Former & $104(12.0)$ & $101(11.7)$ & 0.88 \\
\hline Current & $362(41.6)$ & 255 (29.6) & $<0.0001$ \\
\hline \multicolumn{4}{|l|}{ Betel quid use (n, \%) } \\
\hline Never & $636(73.1)$ & $747(86.7)$ & $<0.0001$ \\
\hline Former & $94(10.8)$ & $43(5.0)$ & $<0.0001$ \\
\hline Current & $140(16.1)$ & $72(8.4)$ & $<0.0001$ \\
\hline \multicolumn{4}{|c|}{ Physical exercise in the past month $(\mathrm{n}, \%)$} \\
\hline Hardly ever & $225(25.9)$ & $127(14.7)$ & $<0.0001$ \\
\hline Once & $86(9.9)$ & $87(10.1)$ & 0.91 \\
\hline Twice or more & $559(64.3)$ & $648(75.2)$ & $<0.0001$ \\
\hline \multicolumn{4}{|l|}{ Poor sleep (n, \%) } \\
\hline Almost never & $600(69.0)$ & $683(79.2)$ & $<0.0001$ \\
\hline Sometimes & $181(20.8)$ & $122(14.2)$ & 0.002 \\
\hline Often or almost always & $89(10.2)$ & $57(6.6)$ & 0.02 \\
\hline Central obesity $(n, \%)$ & $338(38.9)$ & $292(33.9)$ & 0.03 \\
\hline Hypertension (n, \%) & $436(50.1)$ & $353(41.1)$ & 0.0002 \\
\hline Hypertriglyceridemia (n, \%) & $315(36.2)$ & $271(31.4)$ & 0.04 \\
\hline $\begin{array}{l}\text { Low-high-density lipoprotein- } \\
\text { cholesterol (n, \%) }\end{array}$ & $224(25.8)$ & $224(26.0)$ & 0.91 \\
\hline Dysglycemia $(n, \%)$ & $300(34.5)$ & $288(33.4)$ & 0.64 \\
\hline Metabolic syndrome (n, \%) & $276(31.7)$ & $233(27.0)$ & 0.03 \\
\hline
\end{tabular}

$\mathrm{p}<0.0001)$, triglycerides $(\beta=0.25, \mathrm{p}<0.0001)$, uric acid $(\beta=0.10, p<0.0001)$, shift work $(\beta=0.16, p<0.0001)$, and MetS $(\beta=0.22, p<0.0001)$. In addition, HDL-C was significantly negatively associated with both resistin $(\beta=-0.23, \mathrm{p}=0.001)$ and total WBC count $(\beta=-0.20$, $\mathrm{p}<0.0001$ ) (Table 4). Furthermore, resistin was significantly associated with total WBC count $(\beta=0.34$, $\mathrm{p}<0.0001$ ) (Fig. 1).

\section{Discussion}

Our results showed that shift work was significantly associated with MetS. Furthermore, resistin and WBC count may be involved in the pathogenesis of shift work-associated metabolic derangements. To our best of knowledge, 
Table 2 Biochemical characteristics of the study subjects

\begin{tabular}{|c|c|c|c|}
\hline Parameter & Shift work & Day work & $p$ value \\
\hline No & 870 & 862 & \\
\hline Age (years, mean $\pm S D$ ) & $42 \pm 8$ & $43 \pm 8$ & 0.79 \\
\hline $\begin{array}{l}\text { Systolic blood pressure } \\
(\mathrm{mmHg})\end{array}$ & $130 \pm 16$ & $126 \pm 15$ & $<0.0001$ \\
\hline $\begin{array}{l}\text { Diastolic blood pressure } \\
(\mathrm{mmHg})\end{array}$ & $84 \pm 12$ & $81 \pm 11$ & $<0.0001$ \\
\hline Body mass index $\left(\mathrm{kg} / \mathrm{m}^{2}\right)$ & $26.0 \pm 4.0$ & $25.6 \pm 3.8$ & 0.03 \\
\hline Waist circumference (cm) & $88.1 \pm 10.1$ & $81.5 \pm 10.6$ & $<0.0001$ \\
\hline Fasting glucose (mmol/L) & $5.4 \pm 0.8$ & $5.2 \pm 0.4$ & 0.02 \\
\hline $\mathrm{HbA} 1 \mathrm{C}(\%)$ & $5.6 \pm 0.7$ & $5.5 \pm 0.7$ & 0.31 \\
\hline Total cholesterol (mmol/L) & $5.1 \pm 1.1$ & $5.0 \pm 0.9$ & 0.30 \\
\hline Triglyceride (mmol/L) & $1.7 \pm 1.1$ & $1.3 \pm 0.9$ & 0.002 \\
\hline HDL-cholesterol (mmol/L) & $1.2 \pm 0.3$ & $1.3 \pm 0.4$ & 0.002 \\
\hline LDL-cholesterol (mmol/L) & $2.9 \pm 0.9$ & $2.7 \pm 0.8$ & 0.19 \\
\hline Uric acid $(\mu \mathrm{mol} / \mathrm{L})$ & $392.6 \pm 77.3$ & $362.8 \pm 89.2$ & 0.02 \\
\hline Total WBC count $\left(10^{9} / L\right)$ & $6.865 \pm 1.819$ & $6.304 \pm 1.547$ & $<0.0001$ \\
\hline Resistin $(\mathrm{ng} / \mathrm{mL})^{\mathrm{a}}$ & $13 \pm 10$ & $10 \pm 7$ & 0.02 \\
\hline
\end{tabular}

Data are mean \pm SD

$H D L$ high-density lipoprotein, $L D L$ low-density lipoprotein, $W B C$ white blood cell. $\mathrm{p}$ values were calculated using the independent sample $t$ test for numerical data

${ }^{\text {a }}$ Resistin levels were measured in 107 shift workers and 100 day workers

Table 3 Multiple logistic regression analysis with the presence of metabolic syndrome as the dependent variable

\begin{tabular}{lccc}
\hline & Exp(B) & 95\% confidence interval & p value \\
\hline Age & 1.03 & $0.98-1.09$ & 0.22 \\
Alcohol use & 0.33 & $0.07-1.60$ & 0.17 \\
Smoking & 1.07 & $0.50-2.30$ & 0.86 \\
Betel quid use & 2.04 & $0.90-4.64$ & 0.09 \\
Poor physical exercise & 1.05 & $0.45-2.44$ & 0.91 \\
Poor sleep & 0.94 & $0.37-2.38$ & 0.89 \\
Shift work & 2.26 & $1.13-4.51$ & 0.02 \\
\hline
\end{tabular}

this study is the first to show an association between shift work and MetS, and that chronic inflammation induced by shift work may lead to metabolic dysfunction.

Our findings regarding shift work and MetS are consistent with those of previous studies [21-25]. A higher risk of having more MetS components has been reported in a range of occupations including road builders, police officers, nurses, and factory workers in different countries and areas [21, 22, 24-26]. The observed increase in the risk of MetS in shift workers may be explained by several mechanisms. First, a theoretical review showed that sleep and circadian disruption in humans alters the gut microbiota, thereby contributing to an inflammatory state and metabolic disease associated with shift work [27]. Furthermore, shift workers have been reported to gain weight, experience disruption of the circadian rhythm, and impairment of sleep that results in a higher risk of MetS [3, 6, 28-30]. Previous study has also reported associations between night or shift work and increased food intake, a preference for carbohydrate-rich foods, and alterations in lipid parameters, especially triglyceride levels [31]. Moreover, adverse cardiometabolic effects of circadian misalignment produced by shifting eating and sleeping times $12 \mathrm{~h}$ out of phase from habitual times have been shown to result in increased levels of glucose, despite increased levels of insulin, decreased leptin, a completely reversed daily cortisol rhythm, increased mean arterial pressure, and reduced sleep efficiency [32].

Numerous epidemiological and clinical studies have shown that leukocytosis is an independent predictor of insulin resistance, type 2 diabetes, and cardiovascular diseases [33-35]. The elevated peripheral WBC count in the shift workers in the present study may suggest a mechanism for the pathogenesis of shift work-related MetS. The WBC in shift workers may be activated by reactive oxygen species or adipocytokines [36]. Activated leukocytes release many kinds of cytokines, including tumor necrosis factor- $\alpha$, nuclear transcription factorkappaB, and interleukin, superoxide radicals, and proteases, all of which contribute to insulin resistance, MetS, and atherosclerosis [37]. In addition, we also found that plasma resistin levels were higher in the shift workers, and that they were significantly associated with total leukocyte count. We speculate that resistin may enhance the release and activation of leukocytes, and that this is probably the main source of resistin at the site of inflammation which then contributes to the development and progression of insulin resistance and MetS.

Resistin is a circulating protein of 114 amino acids which belongs to the resistin-like family [38]. Resistin is expressed in macrophages and plays an important role in inflammation throughout the body [39]. Several studies from the 2002 to 2008 have also shown that resistin is regulated by insulin, glucose, growth hormone, and thiazolidinediones [40-43]. Rodent studies have suggested that resistin protein is a link between obesity, insulin resistance, and diabetes [44-46]. In addition, Palanivel et al. [47] reported that mice injected with recombinant resistin or overexpressing resistin protein had impaired glucose tolerance and insulin action. Furthermore, Sheng et al. [48] reported that human hepatic cells overexpressing resistin had impaired glucose uptake and glycogen synthesis. Because of its link with obesity, inflammation, and insulin resistance, resistin has been tagged as a potential marker of MetS. In the present study, we found that plasma levels of resistin were significantly increased in the shift workers, suggesting that resistin synthesis or secretion was enhanced. Resistin is a well-known 
Table 4 Association of covariates with total WBC count and resistin

\begin{tabular}{|c|c|c|c|c|}
\hline \multirow[t]{2}{*}{ Factor } & \multicolumn{2}{|l|}{ Total WBC count } & \multicolumn{2}{|l|}{ Resistin } \\
\hline & $\beta$-coefficient $(95 \% \mathrm{Cl})^{\mathrm{a}}$ & $p$ value & $\beta$-coefficient $(95 \% \mathrm{Cl})^{\mathrm{a}}$ & $p$ value \\
\hline Body mass index & 0.25 (0.09 to 0.13$)$ & $<0.0001$ & 0.14 (0.00 to 0.62$)$ & 0.048 \\
\hline Waist circumference & 0.26 (0.04 to 0.05$)$ & $<0.0001$ & $0.12(-0.02$ to 0.21$)$ & 0.10 \\
\hline Systolic BP & 0.16 (0.01 to 0.02$)$ & $<0.0001$ & $0.13(-0.01$ to 0.16$)$ & 0.08 \\
\hline Diastolic BP & 0.15 (0.02 to 0.03$)$ & $<0.0001$ & $0.11(-0.03$ to 0.21$)$ & 0.14 \\
\hline Fasting glucose & 0.09 (0.00 to 0.01$)$ & $<0.0001$ & 0.24 (0.07 to 0.28$)$ & 0.001 \\
\hline $\mathrm{HbA1C}$ & 0.17 (0.23 to 0.41$)$ & $<0.0001$ & 0.15 (0.05 to 3.54) & 0.04 \\
\hline Total cholesterol & 0.04 (0.00 to 0.01$)$ & 0.12 & $-0.01(-0.04$ to 0.03$)$ & 0.90 \\
\hline Triglyceride & 0.25 (0.00 to 0.01$)$ & $<0.0001$ & 0.21 (0.01 to 0.03$)$ & 0.01 \\
\hline HDL-cholesterol & $-0.20(-0.04$ to -0.03$)$ & $<0.0001$ & $-0.23(-0.26$ to -0.06$)$ & 0.001 \\
\hline LDL-cholesterol & 0.03 (- 0.00 to 0.01$)$ & 0.18 & -0.04 ( -0.05 to 0.03$)$ & 0.57 \\
\hline Uric acid & 0.10 (0.07 to 0.19$)$ & $<0.0001$ & 0.11 ( -0.19 to 1.55$)$ & 0.12 \\
\hline Shift work & 0.16 (0.39 to 0.70$)$ & $<0.0001$ & 0.17 (0.49 to 5.38$)$ & 0.02 \\
\hline Metabolic syndrome (NCEP-ATP III) ${ }^{b}$ & 0.22 (0.64 to 0.99$)$ & $<0.0001$ & 0.17 (0.53 to 5.73$)$ & 0.02 \\
\hline
\end{tabular}

WBC white blood cell, $B P$ blood pressure, $H D L$ high-density lipoprotein, $L D L$ low-density lipoprotein

a Adjusted for age using multiple linear regression analysis

b The definition and criteria of NCEP-ATP III metabolic syndrome are described in the text

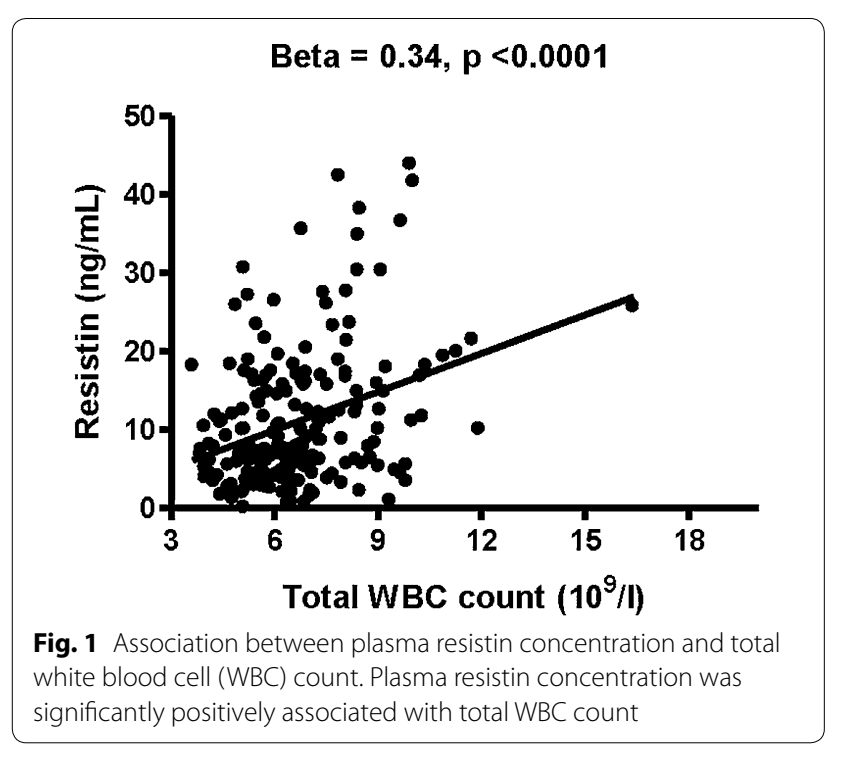

mediator of chronic inflammation that contributes to the pathogenesis of insulin resistance, dyslipidemia, hypertension, MetS, and atherosclerosis [44-46, 49, 50]. Taken together, it is plausible that shift work may induce MetS through a low-grade chronic inflammatory process.

\section{Limitations}

There are several limitations to the present study. First, this was a cross-sectional study and thus it was difficult to investigate the causal relationship between shift work and inflammatory markers. Second, the absence of adequate data for nutrition to assess the daily energy and nutrient intake of the study subjects may have resulted in some bias. Third, we did not consider other confounders that may contribute to the shift work-related development of MetS such as psychosocial stress including income, job, and behavioral stress, and occupational characteristics including tenure, work intensity, and hazardous materials handled at work. Fourth, although we focused on manual workers, a more homogenous population should be selected for future studies as each of our participants had different work tasks, environment, and exposure to hazardous materials, as well as different work schedules according to their education level. Fifth, we did not establish a detailed definition of former shift workers; thus, additional studies may be required to confirm differences in inflammatory markers between past shift workers and recent former shift workers and the reversibility of shift work-induced adverse health effects.

\section{Conclusion}

Our results indicate that shift work is independently associated with a higher prevalence of MetS, and that is has a detrimental influence on central obesity, hypertension, and hyper-triglyceridemia. Chronic inflammation may contribute to shift work-related metabolic derangements. The results of our study raise an important epidemiological issue with regards to MetS, and further large-scale cohort studies are warranted to validate our findings. 


\section{Abbreviations}

MetS: metabolic syndrome; NCEP-ATP III: National Cholesterol Education Program Adult Treatment Panel III; WBC: white blood cell; HDL-C: high-density lipoprotein cholesterol; LDL-C: low-density lipoprotein cholesterol; SBP: systolic blood pressure; DBP: diastolic blood pressure; BMl: body mass index.

\section{Authors' contributions}

Of the 11 authors, Y-CL and C-PW are the first authors who conceived and designed the study and interpreted the data. T-HY, I-TT, W-CH, and J-YH contributed to drafting of the manuscript or revising it critically for important intellectual content. C-CH and I-CL acquired data, drafted the manuscript and designed the study. F-MC and W-HT participated in the design of the study and performed the statistical analysis. M-CYJ is the corresponding author and contributed to the final approval of the manuscript as submitted. All authors read and approved the final manuscript.

\section{Author details}

1 Division of Endocrinologic, E-Da Hospital, l-Shou University, Kaohsiung 82445, Taiwan. ${ }^{2}$ Division of Cardiology, E-Da Hospital, I-Shou University, Kaohsiung 82445, Taiwan. ${ }^{3}$ Division of Gastroenterology and Hepatology, Department of Internal Medicine, E-Da Hospital, I-Shou University, Kaohsiung 82445, Taiwan. ${ }^{4}$ Department of Emergency, E-Da Hospital, I-Shou University, Kaohsiung 82445, Taiwan. ${ }^{5}$ Department of Occupational Medicine, E-Da Hospital, I-Shou University, No. 1, Yi-Da Rd, Jiau-Shu Village, Yan-Chao Township, Kaohsiung 82445, Taiwan. ${ }^{6}$ Department of Nursing, I-Shou University, Kaohsiung 82445, Taiwan. ${ }^{7}$ School of Medicine for International Students, I-Shou University, Kaohsiung 82445, Taiwan. ${ }^{8}$ Department of Nutrition, Institute of Biotechnology and Chemical Engineering, I-Shou University, Kaohsiung 82445, Taiwan. ${ }^{9}$ Division of Cardiology, Department of Internal Medicine, National Yang-Ming University Hospital, Yilan, Taiwan.

\section{Acknowledgements}

The authors wish to thank the participating factories and their employees. The authors would also like to thank the E-Da Hospital of the Republic of China, Taiwan, for financially supporting this research under contracts EDAHP105061 and EDAHP105038.

\section{Competing interests}

The authors declare that they have no competing interests.

\section{Availability of data and materials}

All data generated or analysed during this study are included in this article.

\section{Consent for publication}

Informed consent was obtained from all patients for being included in the study and for using their data for publication. The ethics committee of I-Shou University E-Da Hospital approved this study (EDAH IRB No. EMRP-104-089).

\section{Publisher's Note}

Springer Nature remains neutral with regard to jurisdictional claims in published maps and institutional affiliations.

Received: 18 April 2017 Accepted: 8 October 2017

Published online: 16 October 2017

\section{References}

1. Smith L, Macdonald I, Folkard S, Tucker P. Industrial shift systems. Appl Ergon. 1998;29:273-80.

2. Eastman Cl, Boulos Z, Terman M, Campbell SS, Dijk DJ, Lewy AJ. Light treatment for sleep disorders: consensus report: VI. Shift work. J Biol Rhythm. 1995;10:157-64.

3. Karlsson B, Knutsson A, Lindahl B. Is there an association between shift work and having a metabolic syndrome? Results from a population based study of 27,485 people. Occup Environ Med. 2001;58:747-52.

4. Fujino Y, Iso H, Tamakoshi A, Inaba Y, Koizumi A, Kubo T, Yoshimura T. A prospective cohort study of shift work and risk of ischemic heart disease in Japanese male workers. Am J Epidemiol. 2006;164:128-35.
5. Woo JM, Postolache TT. The impact of work environment on mood disorders and suicide. Evidence and implications. Int J Disabil Hum Dev. 2008;7:185-200.

6. Ohayon MM, Lemoine P, Arnaud-Briant V, Dreyfus M. Prevalence and consequences of sleep disorders in a shift worker population. J Phychosom Res. 2002;53:577-83.

7. Murphy PJ, Campbell SS. Physiology of the circadian system in animals and humans. J Clin Neurophysiol. 1996;13:2-16.

8. Meigs JB, D'Agostino RBS, Wilson PW, Cupples LA, Nathan DM, Singer DE. Risk variable clustering in the insulin resistance syndrome. The Framingham Offspring Study. Diabetes. 1997:46:1594-600.

9. Expert Panel on Detection E. Executive Summary of the Third Report of the National Cholesterol Education Program (NCEP) expert panel on detection, evaluation, and treatment of high blood cholesterol in adults (Adult Treatment Panel III). JAMA. 2001;285:2486-97.

10. Park YW, Zhu S, Palaniappan L, Heshka S, Carnethon MR, Heymsfield SB. The metabolic syndrome: prevalence and associated risk factor findings in the US population from the third national health and nutrition examination survey, 1988-1994. Arch Intern Med. 2003;163:427-36.

11. Dixon JB, Dixon ME, O'Brien PE. Alcohol consumption in the severely obese: relationship with the metabolic syndrome. Obes Res. 2002;10:245-52.

12. Chau NP, Mallion JM, de Gaudemaris R, Ruche E, Siche JP, Pelen O, Mathern $\mathrm{G}$. Twenty four-hour ambulatory blood pressure in shift workers. Circulation. 1989;80:341-7.

13. Di Lorenzo L, De Pergola G, Zocchetti C, L'Abbate N, Basso A, Pannacciulli N, Cignarelli M, Giorgino R, Soleo L. Effect of shift work on body mass index: results of a study performed in 319 glucose-tolerant men working in a Southern Italian industry. Int J Obes Relat Metab Disord. 2003;27:1353-8.

14. Karlsson $\mathrm{BH}$, Knutsson AK, Lindahl BO, Alfredsson LS. Metabolic disturbances in male workers with rotating three-shift work. Results of the WOLF study. Int Arch Occup Environ Health. 2003;76:424-30.

15. Kim SW, Jang EC, Kwon SC, Han W, Kang MS, Nam YH, Lee YJ. Night shift work and inflammatory markers in male workers aged 20-39 in a display manufacturing company. Ann Occup Environ Med. 2016;28:48.

16. Saltiel AR, Olefsky JM. Inflammatory mechanisms linking obesity and metabolic disease. J Clin Invest. 2017;127:1-4.

17. Grundy SM, Cleeman JI, Daniels SR, Donato KA, Eckel RH, Franklin BA, Gordon DJ, Krauss RM, Savage PJ, Smith SC Jr, Spertus JA, Costa F, American Heart Association; National Heart, Lung, and Blood Institute. Diagnosis and management of the metabolic syndrome: an American heart association/national heart, lung, and blood institute scientific statement. Circulation. 2005:112:2735-52.

18. Chung FM, Yang YH, Shieh TY, Shin SJ, Tsai JC, Lee YJ. Effect of alcohol consumption on estimated glomerular filtration rate and creatinine clearance rate. Nephrol Dial Transplant. 2005;20:1610-6.

19. Lu LF, Wang CP, Tsai IT, Hung WC, Yu TH, Wu CC, Hsu CC, Lu YC, Chung FM, Yen Jean MC. Relationship between shift work and peripheral total and differential leukocyte counts in Chinese steel workers. J Occup Health. 2016;58:81-8.

20. Lu YC, Wang CP, Hsu CC, Chiu CA, Yu TH, Hung WC, Lu LF, Chung FM, Tsai IT, Lin HC, Lee YJ. Circulating secreted frizzled-related protein 5 (Sfrp5) and wingless-type MMTV integration site family member 5a (Wnt5a) levels in patients with type 2 diabetes mellitus. Diabetes Metab Res Rev. 2013;29:551-6.

21. Violanti JM, Burchfiel CM, Hartley TA, Mnatsakanova A, Fekedulegn D, Andrew ME, Charles LE, Vila BJ. Atypical work hours and metabolic syndrome among police officers. Arch Environ Occup Health. 2009;64:194-201.

22. Ghiasvand M, Heshmat R, Golpira R, Haghpanah V, Soleimani A, Shoushtarizadeh $P$, Tavangar SM, Larijani B. Shift working and risk of lipid disorders: a cross-sectional study. Lipids Health Dis. 2006;10:9.

23. Brum MC, Filho FF, Schnorr CC, Bottega GB, Rodrigues TC. Shift work and its association with metabolic disorders. Diabetol Metab Syndr. 2015;7:45.

24. Morikawa Y, Nakagawa H, Miura K, Soyama Y, Ishizaki M, Kido T, Naruse Y, Suwazono Y, Nogawa K. Shift work and the risk of diabetes mellitus among Japanese male factory workers. Scand J Work Environ Health. 2005:31:179-83. 
25. Pietroiusti A, Neri A, Somma G, Coppeta L, lavicoli l, Bergamaschi A, Magrini A. Incidence of metabolic syndrome among night-shift healthcare workers. Occup Environ Med. 2010;67:54-7.

26. Jermendy G, Nádas J, Hegyi I, Vasas I, Hidvégi T. Assessment of cardiometabolic risk among shift workers in Hungary. Health Qual Life Outcomes. 2012;10:18

27. Reynolds AC, Paterson JL, Ferguson SA, Stanley D, Wright KP Jr, Dawson $D$. The shift work and health research agenda: considering changes in gut microbiota as a pathway linking shift work, sleep loss and circadian misalignment, and metabolic disease. Sleep Med Rev. 2016. doi:10.1016/j. smrv.2016.06.009.

28. Pan A, Schernhammer ES, Sun Q, Hu FB. Rotating night shift work and risk of type 2 diabetes: two prospective cohort studies in women. PLoS Med. 2011;8:e1001141.

29. Uetani M, Sakata K, Oishi M, Tanaka K, Nakada S, Nogawa K, Suwazono $Y$. The influence of being overweight on the relationship between shift work and increased total cholesterol level. Ann Epidemiol. 2011:21:327-35.

30. Lieu SJ, Curhan GC, Schernhammer ES, Forman JP. Rotating night shift work and disparate hypertension risk in African-Americans. J Hypertens. 2012;30:61-6.

31. Al-Naimi S, Hampton SM, Richard P, Tzung C, Morgan LM. Postprandial metabolic profiles following meals and snacks eaten during simulated night and day shift work. Chronobiol Int. 2004;21:937-47.

32. Scheer FA, Hilton MF, Mantzoros CS, Shea SA. Adverse metabolic and cardiovascular consequences of circadian misalignment. Proc Natl Acad Sci USA. 2009:106:4453-8.

33. Kannel WB, Anderson K, Wilson PW. White blood cell count and cardiovascular disease: insights from the Framingham Study. JAMA. 1992;267:1253-6.

34. Schmidt MI, Duncan BB, Sharrett AR, Lindberg G, Savage PJ, Offenbacher S, Azambuja MI, Tracy RP, Heiss G. Markers of inflammation and prediction of diabetes mellitus in adults (atherosclerosis risk in communities study): a cohort study. Lancet. 1999;353:1649-52.

35. Ford ES. The metabolic syndrome and C-reactive protein, fibrinogen, and leukocyte count: findings from the third national health and nutrition examination survey. Atherosclerosis. 2003;168:351-8.

36. Yasunari K, Maeda K, Nakamura M, Yoshikawa J. Oxidative stress in leukocytes is a possible link between blood pressure, blood glucose, and C-reacting protein. Hypertension. 2002;39:777-80.

37. Eriksson EE. Mechanisms of leukocyte recruitment to atherosclerotic lesions: future prospects. Curr Opin Lipidol. 2004;15:553-8.

38. Steppan CM, Bailey ST, Bhat S, Brown EJ, Banerjee RR, Wright CM, Patel HR, Ahima RS, Lazar MA. The hormone resistin links obesity to diabetes. Nature. 2001;409:307-12.
39. Jamaluddin MS, Weakley SM, Yao Q, Chen C. Resistin: functional roles and therapeutic considerations for cardiovascular disease. Br J Pharmacol. 2012;165:622-32

40. Kawashima J, Tsuruzoe K, Motoshima H, Shirakami A, Sakai K, Hirashima Y, Toyonaga T, Araki E. Insulin down-regulates resistin mRNA through the synthesis of protein(s) that could accelerate the degradation of resistin mRNA in 3T3-L1 adipocytes. Diabetologia. 2003:46:231-40.

41. Shojima N, Sakoda H, Ogihara T, Fujishiro M, Katagiri H, Anai M, Onishi Y, Ono H, Inukai K, Abe M, Fukushima Y, Kikuchi M, Oka Y, Asano T. Humoral regulation of resistin expression in 3T3-L1 and mouse adipose cells. Diabetes. 2002:51:1737-44.

42. Delhanty PJ, Mesotten D, McDougall F, Baxter RC. Growth hormone rapidly induces resistin gene expression in white adipose tissue of spontaneous dwarf (SDR) rats. Endocrinology. 2002;143:2445-8.

43. Wolfing B, Neumeier M, Buechler C, Aslanidis C, Scholmerich J, Schaffler A. Interfering effects of insulin, growth hormone and glucose on adipokine secretion. Exp Clin Endocrinol Diabetes. 2008;116:47-52.

44. Juan CC, Au LC, Fang VS, Kang SF, Ko YH, Kuo SF, Hsu YP, Kwok CF, Ho LT. Suppressed gene expression of adipocyte resistin in an insulin-resistant rat model probably by elevated free fatty acids. Biochem Biophys Res Commun. 2001;289:1328-33.

45. Le Lay S, Boucher J, Rey A, Castan-Laurell I, Krief S, Ferré P, Valet P, Dugail I. Decreased resistin expression in mice with different sensitivities to a high-fat diet. Biochem Biophys Res Commun. 2001;289:564-7.

46. Way JM, Görgün CZ, Tong Q, Uysal KT, Brown KK, Harrington WW, Oliver WR Jr, Willson TM, Kliewer SA, Hotamisligil GS. Adipose tissue resistin expression is severely suppressed in obesity and stimulated by peroxisome proliferatoractivated receptor gamma agonists. J Biol Chem. 2001:276:25651-3.

47. Palanivel R, Maida A, Liu Y, Sweeney G. Regulation of insulin signalling, glucose uptake and metabolism in rat skeletal muscle cells upon prolonged exposure to resistin. Diabetologia. 2006;49:183-90.

48. Sheng $C H$, Di J, Jin Y, Zhang YC, Wu M, Sun Y, Zhang GZ. Resistin is expressed in human hepatocytes and induces insulin resistance. Endocrine. 2008;33:135-43.

49. Reilly MP, Lehrke M, Wolfe ML, Rohatgi A, Lazar MA, Rader DJ. Resistin is an inflammatory marker of atherosclerosis in humans. Circulation. 2005:111:932-9.

50. Gupta V, Singh AK, Gupta V, Kumar S, Srivastava N, Jafar T, Pant AB. Association of circulating resistin with metabolic risk factors in Indian females having metabolic syndrome. Toxicol Int. 2011;18:168-72.

\section{Submit your next manuscript to BioMed Central and we will help you at every step:}

- We accept pre-submission inquiries

- Our selector tool helps you to find the most relevant journal

- We provide round the clock customer support

- Convenient online submission

- Thorough peer review

- Inclusion in PubMed and all major indexing services

- Maximum visibility for your research

Submit your manuscript at www.biomedcentral com/submit
(OioMed Central 